\title{
ANALISIS PROSEDUR PENERBITAN SURAT PERSETUJUAN PENGELUARAN BARANG (SPPB) PADA KANTOR PENGAWASAN DAN PELAYANAN BEA DAN CUKAI TIPE MADYA PABEAN C MANADO
}

\author{
Widya Maruru $^{1}$, Jullie Sondakh ${ }^{2}$, Sintje Rondonuwu $^{3}$ \\ ${ }^{1,2,3}$ Fakultas Ekonomi dan Bisnis. Jurusan Akuntansi. Universitas Sam Ratulangi, Jl. Kampus Bahu, Manado, \\ 95115, Indonesia
}

E-mail : wmaruru@gmail.com

\begin{abstract}
The one way to be able to control and supervise issuance of Approval Letter of Expenditure of Goods (SPPB) of import by carrying out the procedures and rules that apply. In the regulation of the Director General of Customs and Excise No. PER-16/BC/2016 concerning Hints Implementation Spending Goods Import For Used, explain about system work service Notice Import Goods (PIB) to on publishing Letter Approval Spending Goods (SPPB). Aim research this is for knowing procedure publishing Letter Objection Spending Goods (SPPB) on Oversight Office and Customs and Excise Type Madya Customs C Manado already corresponding or not yet corresponding with regulations director General of Customs and Excise No. PER-16 / BC / 2016. Research this use method research qualitatively. Results from research this that is procedure publishing Letter Approval Spending Goods (SPPB) already corresponding with rules director Jen deral Customs and Excise Number: PER -1 6 / BC / 2016. D iharapkan K antor Supervision and Customs and Excise Type Madya Customs C Manado continue improve quality in publishing Letter Approval Spending Goods (SPPB) imports, because now this so many goods imports coming in dae rah customs and need accuracy in p examination from stage importer fill and make Notice Import (PIB) to publishing Letter Approval Spending Goods (SPPB) so as not happen import prohibited goods sign in to in area customs and no reduce State revenue.
\end{abstract}

Keywords : Procedures, rules, SPPB, import.

\section{PENDAHULUAN}

Dalam era perkembangan perekonomian Indonesia saat ini sudah begitu banyak kegiatan impor yang terjadi, sehingga Direktorat Jenderal Bea dan Cukai (DJBC) harus lebih bijak lagi dalam hal pengawasan kegiatan impor. As the world economy shifts into a more globalized era, presently every developing nation is harnessing their resources in aneffort to take part in a more free trade regime (Juita:2012). Untuk memudahkan para importir melakukan impor, Direktorat Jenderal Bea dan Cukai (DJBC) mengeluarkan peraturan Nomor : PER-16/BC/2016 tentang Petunjuk Pelaksanaan Pengeluaran Barang Impor Untuk Dipakai. Pengertian barang impor untuk dipakai menurut Undang-Undang Republik Indonesia Nomor 17 tahun 2006 tentang perubahan atas Undang-Undang Nomor 10 tahun 1995 tentang Kepabeanan pasal 10B ayat 1 yaitu memasukkan barang ke dalam daerah pabean dengan tujuan untuk dipakai atau memasukkan barang ke dalam daerah pabean untuk dimiliki atau dikuasai oleh orang yang berdomisili di Indonesia, dan pada pasal 10B ayat 2 Barang impor dapat dikeluarkan sebagai barang impor untuk dipakai setelah diserahkan pemberitahuan pabean dan dilunasi bea masuknya, diserahkan pemberitahuan pabean dan jaminan sebagaimana dimaksud dalam Pasal 42, atau diserahkan dokumen pelengkap pabean dan jaminan sebagaimana dimaksud dalam Pasal 42. Kegiatan impor, harus diikuti oleh pemenuhan kewajiban kepabeanan, seperti penyampaian pemberitahuan pabean, pembayaran bea masuk dan pajak dalam rangka impor dan kelengkapan dokumen-dokumen yang diperlukan dalam penelitian dokumen dan pemeriksaan fisik atas barang. Kegiatan importasi 
ini tidak terlepas dari ketentuan-ketentuan dalam perdagangan, Angka Pengenal Impor (API) yaitu, tanda pengenal sebagai importir yang harus dimiliki setiap perusahaan yang melakukan perdagangan impor, Purwito (2015: 10).

Dimana pada sekarang ini prosedur penerbitan Surat Persetujuan Pengeluaran Barang (SPPB) impor sudah menggunakan Sistem Komputer Pabean (SKP) atau secara elektronik. Dalam aturan PER-16/BC/2016 tentang Petunjuk Pelaksanaan Pengeluaran Barang Impor Untuk Dipakai, penerbitan Surat Persetujuan Pengeluaran Barang (SPPB) impor ditetapkan tiga jalur pengeluaran barang impor yaitu jalur hijau, jalur kuning dan jalur merah. Penetapan jalur pengeluaran barang Impor dilakukan berdasarkan profil atas operator ekonomi, profil komoditi, pemberitahuan pabean, metode acak dan informasi intelijen. Dan dengan adanya Sistem Komputer Pabean (SKP) Kantor Pengawasan dan Pelayanan Bea dan Cukai tentunya memberikan kemudahan pada para importir untuk melakukan kegiatan impor, hal ini tentunya menarik untuk diteliti untuk mengetahui apakah Kantor Pengawasan dan Pelayanan Bea dan Cukai dalam mengawasi para importir melakukan kegiatan impor, sudah berdasaran aturan yang berlaku atau tidak. Adapun tujuan yang ingin dicapai dalam penelitian ini adalah untuk mengetahui prosedur penerbitan Surat Pesretujuan Pengeluaran Barang (SPPB) pada Kantor Pengawasan dan Pelayanan Bea dan Cukai Tipe Madya Pabean C Manado sudah sesuai atau belum sesuai dengan peraturan Direktur Jenderal Bea dan Cukai Nomor: PER-16/BC/2016.

\section{TINJAUAN PUSTAKA}

\subsubsection{Pengertian Akuntansi}

Akuntansi merupakan sistem informasi yang menyediakan laporan bagi para pihak pengambil keputusan (Stakeholder) mengenai aktivitas ekonomi dan kondisi perusahaan. Di dalam penerapannya akuntansi mengikuti prinsip-prinsip akuntansi yang berlaku secara umum, sehingga memungkinkan para stakeholder untuk membandingkan kinerja perusahaan dengan perusahaan lain sejenis, Lubis (2015:2).

\subsubsection{Pengertian Akuntansi Perpajakan}

Supriyanto (2011:2) menyatakan akuntansi perpajakan adalah suatu proses pencatatan, penggolongan dan pengikhtisaran suatu transaksi keuangan kaitannya dengan kewajiban perpajakan dan diakhiri dengan pembuatan laporan keuangan fiskal sesuai dengan ketentuan dan peraturan perpajakan yang terkait sebagai dasar pembuatan Surat Pemberitahuan Tahunan.

Seperti yang dikutip dalam (Johanes T, Jullie S, Jessy W: 2017), dengan meningkatnya penerimaan negara dalam sektor pajak sangat membantu pemerintah untuk mengurangi adanya defisit anggaran dan ketergantungan akan bantuan dan pinjaman luar negeri.

\subsection{Impor}

Konsep impor berasal dari adanya kegiatan dalam perdagangan internasional, terkait dengan adanya jual beli barang yang dilakukan lintas Negara. Kegiatan impor, harus diikuti oleh pemenuhan kewajiban kepabeanan, seperti penyampaian pemberitahuan pabean, pembayaran bea masuk dan pajak dalam rangka impor dan kelengkapan-kelengkapan dokumen yang diperlukan dalam penelitian dokumen dan pemeriksaan fisik atas barang, Purwito (2015:10).

\section{Pengertian Impor}

Menurut Undang-Undang Republik Indonesia Nomor 17 tahun 2006 perubahan atas Undang-Undang Nomor 10 tahun 1995 Tentang Kepabeanan, impor adalah kegiatan memasukkan barang ke dalam daerah pabean.

\section{Tarif Impor}

Menurut Mardiasmo (2016:271) besarnya tarif impor yaitu :

1. Yang menggunakan Angka Pengenal Impor (API) yaitu 2,5\% dari nilai impor. 
2. Yang tidak menggunakan Angka Pengenal Impor (API) yaitu 75\% dari nilai impor.

\section{Komoditi Dalam Impor}

Menurut Purwito (2015:11), pembagian komoditi di bawah ini secara umum sesuai dengan tujuan pemakaiannya, yaitu :

1. Bahan baku, adanya sifat ketergantungan dalam perdagangan internasional dan industri dalam negeri, dapat dipenuhi selain pembelian bahan baku pokok atau bahan pendamping dalam negeri, juga melalui importisasi. Indonesia mengimpor berbagai jenis bahan baku untuk kebutuhan industri. Bahan baku industri berupa bahan baku pokok dan bahan pendamping.

2. Barang-barang konsumsi, terbanyak importasi yang dilakukan oleh importir saat ini adalah barang konsumsi, yaitu barang yang digunakan untuk memenuhi kebutuhan rumah tangga sehari-hari.

3. Barang permainan anak-anak, membanjirnya barang-barang murah untuk mainan anak-anak, mengakibatkan keamanan dan kesehatan terhadap pemakainya banyak diabaikan.

\section{Impor Untuk Dipakai}

Impor untuk dipakai adalah memasukkan barang ke dalam Daerah Pabean dengan tujuan untuk dipakai, artinya barang impor tersebut akan dijual kembali atau digunakan, habis dikonsumsi, dimiliki atau dipakai oleh pemakai akhir. Atau memasukkan barang ke dalam Daerah Pabean untuk dimiliki atau dikuasai oleh orang yang berdomisili di Indonesia. Pada dasrnya melakukan impor atau memasukkan barang ke dalam Daerah Pabean, dapat dilaksanakan setelah semua persyaratan pemenuhan kewajiban pabean sudah dipenuhi, seperti membayar bea masuk dan pajak dalam rangka impor yang terutang, Purwito (2015:12).

\subsection{Surat Persetujuan Pengeluaran Barang (SPPB) \\ Tatalaksana Pemeriksaaan Barang Impor}

Dalam Undang-Undang Republik Indonesia Nomor 17 tahun 2006 perubahan atas Undang-Undang Nomor 10 tahun 1995 Tentang Kepabeanan pada pasal 3 menyebutkan bahwa, terhadap barang impor dilakukan pemeriksaan pabean. Pemeriksaan pabean sebagaimana dimaksud meliputi penelitian dokumen dan pemeriksaan fisik barang pemeriksaan pabean sebagaimana dilakukan secara selektif.

Kementerian Keuangan Republik Indonesia salinan peraturan Direktur Jenderal Bea dan Cukai Nomor : PER-16/BC/2016 tentang petunjuk Pelaksanaan Pengeluaran Barang Impor Untuk Dipakai, pasal 24 menjelaskan dalam rangka pemeriksaan pabean secara selektif, ditetapkan jalur pengeluaran barang Impor.

\section{Penetapan Jalur}

Penetapan jalur menurut Purwito (2015:147).

1. Jalur merah adalah mekanisme pelayanan dan pengawasan barang impor dengan dilakukan pemeriksaan fisik dan penelitian dokumen sebelum penerbitan Surat Persetujuan Pengeluaran Barang (SPPB).

2. Jalur kuning adalah mekanisme palayanan dan pengawasan pengeluaran barang impor dengan tidak melakukan pemeriksaan fisik tetapi melakukan penelitian dokumen sebelum penerbitan Surat Persetujuan Pengeluaran Barang Impor (SPPB).

3. Jalur hijau adalah mekanisme pelayanan dan pengawasan pengeluaran barang impor dengan tidak dilakukan pemeriksaan fisik. Penelitian dokumen dilakukan setelah penerbitan Surat Persetujuan Pengeluaran Barang (SPPB) dikeluarkan.

\section{Penerbitan SPPB dan Pengeluaran Barang Impor}

Peraturan Kementrian Keuangan Republik Indonesia salinan peraturan Direktur Jenderal Bea dan Cukai Nomor : PER-16/BC/2016 tentang Petunjuk Pelaksanaan Pengeluaran Barang Impor Untuk Dipakai, merupakan aturan yang berlaku dalam mengawasi pengeluaran barang impor. 


\subsection{Bea Masuk}

Importir bertanggung jawab atas Bea Masuk barang yang diimpor melalui sistem menghitung dan membayar sendiri Bea Masuk yang terutang. Bea Masuk dilunasi selambatlambatnya pada saat barang akan dikeluarkan dari kawasan pabean (kecuali impor yang biayanya ditangguhkan atau dibebaskan).

\section{Pengertian Bea Masuk}

Menurut Purwito (20015:106), Bea Masuk merupakan sejumlah uang yang dipungut dan dikumpulkan oleh Negara bersifat memaksa terhadap orang yang melakukan kegiatan pemasukan barang dari luar daerah pabean ke dalam daerah pabean oleh otoritas kepabeanan sesuai dengan ketentuan perundang-undangan yang mengatur atas pemakainan, kepemilikan, penggunaan sementara atau dimasukkan kembali atas barang tersebut.

\section{Karakteristik Pemungutan Bea Masuk}

Menurut Purwito (2015:105), pemungutan bea masuk dilakukan terhadap importasi barang yang berasal dari luar daerah pabean. Pungutan yang merupakan pajak tidak langsung yang berdasarkan asas self assessment dibayar oleh importir pada saat pemberitahuan. Bea masuk hanya dipungut apabila importasi dilakukan atas barang untuk dipakai atau apabila barang dimaksud tidak dikeluarkan untuk dipakai atau apabila barang dimaksud tidak dikeluarkan untuk dijual atau dimiliki.

\section{Perhitungan Bea Masuk}

Perhitungan Bea Masuk (BM)

PPN

PPh Impor

\author{
$=$ Nilai Cost Insurance and Freight (CIF) $\times$ \\ Kurs $\times$ Tarif BM \\ $=10 \%($ Nilai Pabean + BM) \\ (Nilai Pabean $=$ CIF $\times$ Kurs) \\ $=2,5 \% \times($ Nilai Pabean $+\mathrm{BM})$
}

\section{Dasar Hukum Bea Masuk}

1. Undang-Undang Republik Indonesia Nomor 17 Tahun 2006 tentang perubahan atas Undang-Undang Nomor 10 Tahun 1995 tentang Kepabeanan.

2. Peraturan Menteri Keuangan Nomor 34/PMK.04/2016 tentang perubahan atas Peraturan Menteri Keuangan Nomor 160/PMK.04/2010 tentang Nilai Pabean Untuk Penghitungan Bea Masuk.

\subsection{Penelitian Terdahulu}

1. David Sandro Simorangkir (2017) dengan judul Evaluasi Implementasi Peranan Pengendalian Internal: Pelaksanaan Impor Sementara di Kantor Pengawasan dan Pelayanan Bea dan Cukai Tipe Madya X. Tujuan penelitian Mengevaluasi pelaksanaan impor sementara di Kantor Pengawasan dan Pelayanan Bea dan Cukai (KPBBC) Tipe Madya X melalui evaluasi pengendalian internal. Metode yang digunakan kualitatif. Hasil peneltian menunjukan Kantor Pelayanan dan Pengawasan Bea Cukai (KPPBC) Tipe Madya X telah memiliki pengurusan perizinan impor sementara yang baik, namun terdapat prosedur yang belum dilaksanakan sesuai dengan aturan.

2. Lina Ardi Arti (2016) dengan judul Proses Penanganan Custom Clearance Akibat Kesalahan Pemberitahuan Impor Barang Pada PT. Mitra Kargo Indonesia. Tujuan penelitian Untuk mengidentifikasi proses penanganan custom clearance akibat kesalahan pemberitahuan impor barang pada PT Mitra Kargo Indonesia. Metode yang digunakan Deskriptif Kualitatif. Hasil penelitian menunjukan Peranan PT Mitra Kargo Indonesia dalam proses penanganan custom clearance adalah sebagai freight forwader yang mewakili importir untuk melakukan pengeluaran barang impor. Dimana freight forwader membantu pengurusan dokumen impor yang dibutuhkan untuk custom clearance sampai barang keluar dan sampai pada gudang importir. Dokumen yang diperlukan untuk custom clearance terkait kesalahan 
pemberitahuan impor barang antara lain Bill of Lading, Packing List, Invoice, PIB, Asuransi,BKPM,Delivery Order, SPTNP.

\section{METODE PENELITIAN}

\subsection{Jenis Penelitian}

Jenis penelitian yang digunakan dalam penelitian ini yaitu, penelitian kualitatif. Menurut Indrawati (2015:206), penelitian kualitatif adalah metode penelitian yang melibatkan analisi data berupa deskriptif dan data tersebut tidak secara langsung dapat dikuantifikasi.

\subsection{Tempat dan Waktu Penelitian}

Penelitian ini dilakukan di Kantor Pengawasan dan Pelayanan Bea dan Cukai Tipe Madya Pabean C Manado, yang berlokasi di Jalan A.A. Maramis, Paniki Bawah, Mapanget, Manado. Waktu Penelitian mulai dari bulan Februari 2017 sampai bulan Juni 2017.

\subsection{Metode Pengumpulan Data \\ Jenis Data}

Menurut (Sugiyono 2012 : 7), jenis data menurut sifatnya terdiri dari kuantitatif dan kualitatif yaitu :

1. Kuantitatif dapat diartikan sebagai metode penelitian yang berlandaskan pada filsafat positivisme, digunakan untuk meneliti pada populasi atau sampel tertentu. Teknik pengambilan sampel pada umumnya dilakukan secara random, pengumpulan data menggunakan instrumen penelitian, analisis data bersifat kuantitatif atau statistik dengan tujuan untuk menguji hipotesis yang telah ditetapkan.

2. Kualitatif merupakan metode baru karena popularitasnya belum lama, metode ini juga dinamakan postpositivistik karena berlandaskan pada filsafat post positifisme, serta sebagai metode artistic karena proses penelitian lebih bersifat seni (kurang terpola), dan disebut metode interpretive karena data hasil peneletian lebih berkenaan dengan interprestasi terhadap data yang di temukan di lapangan.

\section{Sumber Data}

1. Data primer

Sumber data yang digunakan dalam penelitian ini, yaitu :

Data yang diperoleh langsung dari pegawai Kantor Pengawasan dan Pelayanan Bea dan Cukai Tipe Madya Pabean C Manado.

2. Data sekunder

Data yang diperoleh langsung dari pegawai Kantor Pengawasan dan Pelayanan Bea dan Cukai Tipe Madya Pabean C Manado, buku-buku dan jurnal.

\section{Teknik Pengumpulan Data}

1. Penelitian Kepustakaan

2. Penelitian Lapangan (wawancara dan dokumentasi)

\subsection{Metode Analisis}

Model analisi yang digunakan dalam penelitian ini yaitu metode analisis deskriptif kualitatif. Dengan cara menggambarkan kenyataan atau keadaan atas suatu objek dalam bentuk uraian kalimat berdasarkan keterangan dari pihak yang bersangkutan langsung dengan penelitian ini. 


\section{HASIL ANALISIS DAN PEMBAHASAN}

Tabel 4.2

Perbandingan Antara PER-16/BC/2016 dan Prosedur Penerbitan Surat Persetujuan Pengeluaran Barang (SPPB) Pada Kantor Pengawasan dan Pelayanan Bea dan Cukai Tipe Madya Pabean C Manado

\begin{tabular}{|c|c|c|c|}
\hline NO & $\begin{array}{c}\text { PERATURAN DIREKTUR } \\
\text { JENDERAL BEA DAN } \\
\text { CUKAI } \\
\text { NOMOR:PER16/BC/2016 }\end{array}$ & $\begin{array}{c}\text { PENERBITAN SPPB DI } \\
\text { KANTOR } \\
\text { PENGAWASAN DAN } \\
\text { PELAYANAN BEA DAN } \\
\text { CUKAI TIPE MADYA } \\
\text { PABEAN C MANADO }\end{array}$ & KETERANGAN \\
\hline 1. & $\begin{array}{l}\text { Importir mengisi dan membuat } \\
\text { PIB dalam bentuk data } \\
\text { elektronik. }\end{array}$ & $\begin{array}{l}\text { Pemberitahuan } \\
\begin{array}{l}\text { Barang } \\
\text { internet. }\end{array}\end{array}$ & $\begin{array}{l}\text { Sudah sesuai, karena Pemberitahuan } \\
\text { Impor Barang (PIB) berlangsung } \\
\text { secara online. }\end{array}$ \\
\hline 2. & $\begin{array}{l}\text { SKP menerima data PIB dan } \\
\text { melakukan penelitian ada atau } \\
\text { tidaknya } \\
\text { importir. }\end{array}$ & $\begin{array}{l}\text { SKP akan melakukan } \\
\text { validasi terhadap data yang } \\
\text { diajukan. }\end{array}$ & $\begin{array}{l}\text { Sudah sesuai, pemeriksaan data PIB } \\
\text { pada Kantor Pengawasan dan } \\
\text { Pelayanan Bea dan Cukai Tipe } \\
\text { Madya Pabean C Manado. }\end{array}$ \\
\hline 3. & $\begin{array}{l}\text { Dalam hal pengisian data PIB } \\
\text { tidak sesuai SKP mengirim } \\
\text { respons penolakan dan importir } \\
\text { melakukan perbaikan PIB sesuai } \\
\text { respons penolakan dan } \\
\text { mengirimkan kembali PIB yang } \\
\text { telah diperbaiki. }\end{array}$ & $\begin{array}{l}\text { Kalau data tidak valid maka } \\
\text { dokumen akan di reject, } \\
\text { kalau dokumen tersebut } \\
\text { valid maka importir akan } \\
\text { memperoleh nomor } \\
\text { pendaftaran. Kurangnya } \\
\text { berkas yang tidak valid. }\end{array}$ & $\begin{array}{l}\text { Sudah sesuai, sebagian besar } \\
\text { dokumen diterima. }\end{array}$ \\
\hline 4. & $\begin{array}{l}\text { SKP memberikan tanggal } \\
\text { pengajuan dan menerbitkan } \\
\text { kode billing pembayaran. }\end{array}$ & $\begin{array}{l}\text { Setelah mendapatkan } \\
\text { nomor pendaftaran, SKP } \\
\text { akan memberikan secara } \\
\text { otomat kode billing. }\end{array}$ & $\begin{array}{l}\text { Sudah sesuai antara aturan dan } \\
\text { prosedur di Kantor Pengawasan dan } \\
\text { Pelayanan Bea dan Cukai Tipe } \\
\text { Madya Pabean C Manado. }\end{array}$ \\
\hline 5. & $\begin{array}{l}\text { Importir melakukan pembayaran } \\
\text { bea masuk sesuai kode billing } \\
\text { pembayaran. Batas pembayaran } \\
\text { selama } 5 \text { hari. }\end{array}$ & $\begin{array}{l}\text { Berdasarkan kode billing } \\
\text { importir harus melakukan } \\
\text { pembayaran, } \\
\text { pembayaran } 7 \text { hari. }\end{array}$ & $\begin{array}{l}\text { Untuk pembayaran setelah menerima } \\
\text { kode billing sudah sesuai, tetapi } \\
\text { Kantor Pengawasan dan Pelayanan } \\
\text { Bea dan Cukai Tipe Madya Pabean } \\
\text { C Manado seharusnya memberikan } \\
\text { kesempatan importir membayar } \\
\text { selama } 5 \text { hari bukan } 7 \text { hari. }\end{array}$ \\
\hline 6. & $\begin{array}{lrr}\text { Dalam hal importir } & \text { telah } \\
\text { melakukan pembayaran. } & \text { maka } \\
\text { SKP menetapkan } & \text { jalur } \\
\text { pengeluaran barang impor. }\end{array}$ & $\begin{array}{l}\text { Setelah } \\
\text { pembayaran, SKP akan } \\
\text { melakukan penjaluran. } \\
\text { Penjaluran ditetapkan } \\
\text { berdasarkan analisis resiko } \\
\text { pada profil importer dan } \\
\text { profil komoditi atau secara } \\
\text { acak. }\end{array}$ & $\begin{array}{l}\text { Sudah sesuai antara aturan dan } \\
\text { pelaksanaan di Kantor Pengawasan } \\
\text { dan Pelayanan Bea dan Cukai Tipe } \\
\text { Madya Pabean C Manado. }\end{array}$ \\
\hline
\end{tabular}




\begin{tabular}{|c|c|c|c|}
\hline NO & $\begin{array}{c}\text { PERATURAN DIREKTUR } \\
\text { JENDERAL BEA DAN } \\
\text { CUKAI } \\
\text { NOMOR:PER16/BC/2016 }\end{array}$ & $\begin{array}{c}\text { PENERBITAN SPPB DI } \\
\text { KANTOR } \\
\text { PENGAWASAN DAN } \\
\text { PELAYANAN BEA DAN } \\
\text { CUKAI TIPE MADYA } \\
\text { PABEAN C MANADO }\end{array}$ & KETERANGAN \\
\hline 7. & $\begin{array}{l}\text { Jika pengeluaran barang impor } \\
\text { ditetapkan melalui jalur hijau, } \\
\text { SKP mengirim menerbitkan } \\
\text { SPPB kepada Importir. Importir } \\
\text { menerima respons SPPB dan } \\
\text { mencetaknya untuk } \\
\text { pengeluaran barang dari } \\
\text { kawasan pabean. }\end{array}$ & $\begin{array}{l}\text { Jika importir terkena jalur } \\
\text { hijau, setelah dokumen } \\
\text { diajukan importir langsung } \\
\text { mendapatkan SPPB. }\end{array}$ & $\begin{array}{l}\text { Sudah sesuai atas penerbitan SPPB } \\
\text { melalui jalur hijau. }\end{array}$ \\
\hline 8. & $\begin{array}{l}\text { Jika pengeluaran barang impor } \\
\text { ditetapkan melalui jalur kuning, } \\
\text { SKP mengirim SPJK kepada } \\
\text { Importir, importir menerima } \\
\text { respons SPJK, dan PFPD } \\
\text { melakukan pemeriksaan } \\
\text { terhadap dokumen. Pejabat } \\
\text { pemeriksa dokumen dapat } \\
\text { mengirim respons melalui SKP } \\
\text { berupa permintaan tambahan } \\
\text { keterangan dalam rangka } \\
\text { penelitian tarif dan nilai pabean. } \\
\text { Dalam hasil pemeriksaan impor } \\
\text { tidak mengakibatkan } \\
\text { kekurangan pembayaran, SKP } \\
\text { akan menerbitkan SPPB. } \\
\text { Tetapi jika dalam pemeriksaan } \\
\text { dokumen mengakibatkan } \\
\text { kekurangan pembayaran, PFPD } \\
\text { menerbitkan SPTNP dan } \\
\text { mengirimkan respons SPTNP } \\
\text { serta kode billing kepada } \\
\text { importir yang wajib dibayar. } \\
\text { Jika importir telah melunasi } \\
\text { kekurangan pembayaran } \\
\text { berdasarkan SPTNP, SKP } \\
\text { menerbitkan Surat Persetujuan } \\
\text { Pengeluaran Barang (SPPB). }\end{array}$ & 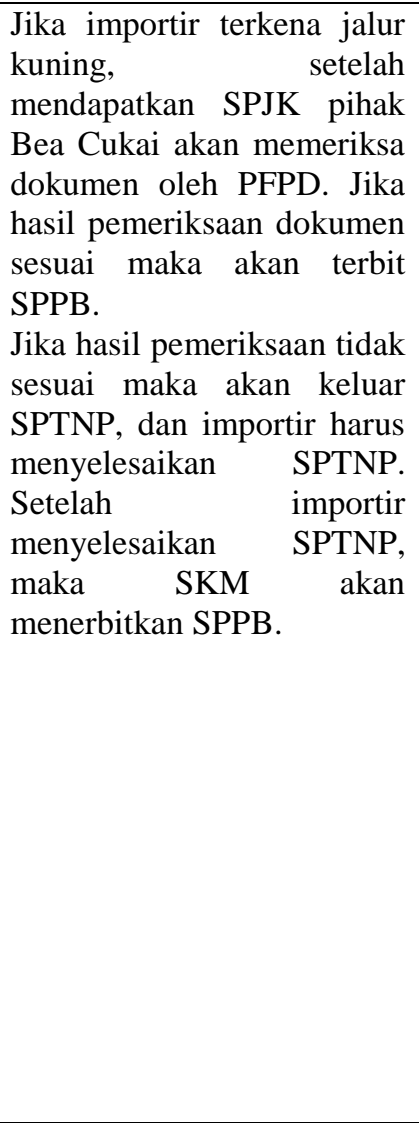 & $\begin{array}{l}\text { Sudah sesuai, Kantor Pengawasan } \\
\text { dan Pelayanan Bea dan Cukai Tipe } \\
\text { Madya Pabean C Manado } \\
\text { menjalankan prosedur penerbitan } \\
\text { SPPB melalui jalur kuning sudah } \\
\text { sesuai dengan aturan PER- } \\
\text { 16/BC/2016. }\end{array}$ \\
\hline 9 & $\begin{array}{l}\text { JIka pengeluaran barang impor } \\
\text { ditetapkan melalui Jalur Merah, } \\
\text { SKP mengirim respons SPJM } \\
\text { kepada Importir } \\
\text { SKP menunjuk Pejabat } \\
\text { pemeriksa fisik dan menerbitkan } \\
\text { IP. Pejabat pemeriksa fisik } \\
\text { menerima instruksi } \\
\text { pemeriksaan, hasil cetak PIB. } \\
\text { Pejabat pemeriksa fisik } \\
\text { melakukan pemeriksaan fisik } \\
\text { barang, LHP dan membuat BAP } \\
\text { fisik. Pejabat pemeriksa fisik }\end{array}$ & $\begin{array}{l}\text { Jika importir terkena jalur } \\
\text { merah, setelah mendapatkan } \\
\text { SPJM. Pihak Bea Cukai } \\
\text { akan memberikan surat } \\
\text { pemberitahuan pemeriksa } \\
\text { fisik, setelah itu SKP akan } \\
\text { mengeluarkan instruksi } \\
\text { pemeriksaan (IP) fisik } \\
\text { sebagai dasar pemeriksaan } \\
\text { untuk melakukan } \\
\text { pemeriksaan fisik. Setelah } \\
\text { itu pemeriksa fisik } \\
\text { membuat LHP, Setelah itu }\end{array}$ & $\begin{array}{l}\text { Sudah Sesuai, pada jalur merah } \\
\text { Kantor Pengawasan dan Pelayanan } \\
\text { Bea dan Cukai Tipe Madya Pabean } \\
\text { C Manado menjalankan prosedur } \\
\text { penerbitan SPPB sudah sesuai } \\
\text { dengan PER-16/BC/2016. }\end{array}$ \\
\hline
\end{tabular}




\begin{tabular}{|c|c|c|c|}
\hline NO & $\begin{array}{c}\text { PERATURAN DIREKTUR } \\
\text { JENDERAL BEA DAN } \\
\text { CUKAI } \\
\text { NOMOR:PER16/BC/2016 }\end{array}$ & $\begin{array}{c}\text { PENERBITAN SPPB DI } \\
\text { KANTOR } \\
\text { PENGAWASAN DAN } \\
\text { PELAYANAN BEA DAN } \\
\text { CUKAI TIPE MADYA } \\
\text { PABEAN C MANADO }\end{array}$ & KETERANGAN \\
\hline & 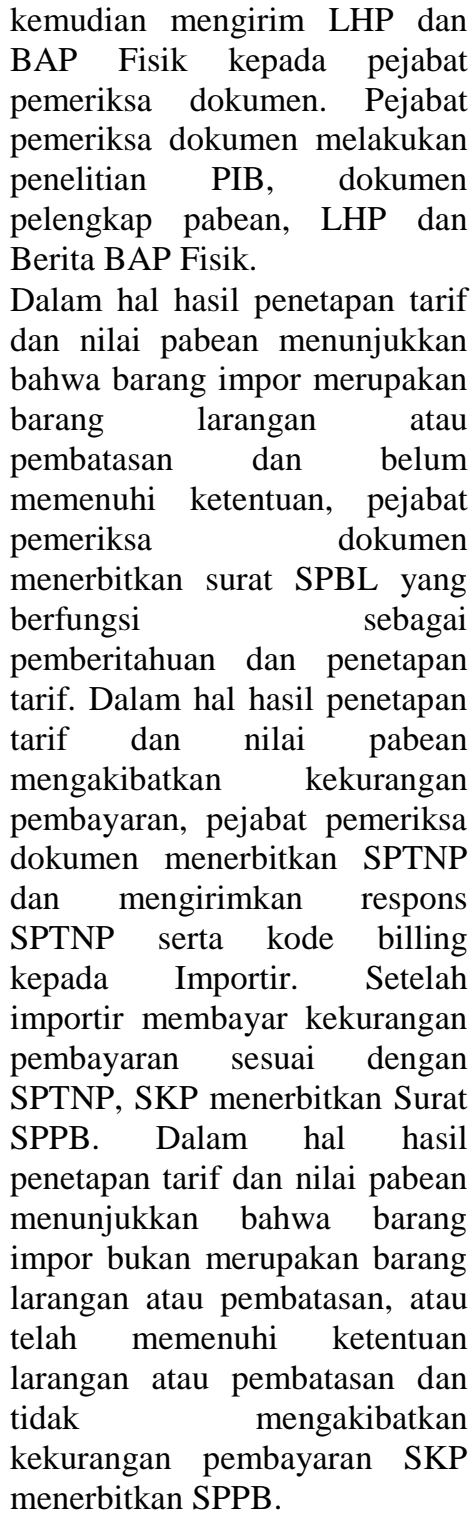 & $\begin{array}{lr}\text { akan dilakukan } \\
\text { pemeriksaan fisik oleh } \\
\text { PFPD. Hasil pemeriksaan } \\
\text { bisa sesuai dan tidak sesuai. } \\
\text { Jika pemeriksaan fisik dan } \\
\text { dokumen sesuai maka akan } \\
\text { terbit SPPB. JIka hasil } \\
\text { pemeriksaan tidak sesuai } \\
\text { maka akan keluar SPTNP. } \\
\text { Importir } \\
\text { menyelesaikan harus } \\
\text { setelah SPTNP, } \\
\text { pembayaran maka SKP } \\
\text { akan menerbitkan SPPB } \\
\text { secara otomatis. }\end{array}$ & \\
\hline
\end{tabular}

Sumber : Data diolah.

Berdasarkan hasil perbandingan antara prosedur penerbitan Surat Persetujuan Pengeluaran Barang (SPPB) pada Kantor Pengawasan dan Pelayanan Bea dan Cukai Tipe Madya Pabean $\mathrm{C}$ Manado dengan peraturan Kementrian Keuangan Republik Indonesia salinan peraturan Direktur Jenderal Bea dan Cukai Nomor : PER-16/BC/2016 tentang Petunjuk Pelaksanaan Pengeluaran Barang Impor Untuk Dipakai, menunjukan bahwa pada prosedur penerbitan Surat Persetujuan Pengeluaran Barang (SPPB) sudah sesuai dengan aturan yang berlaku. Tetapi pada prosedur nomor 5 seharusnya Kantor Pengawasan dan Pelayanan Bea dan Cukai Tipe Madya Pabean C Manado memberikan kesempatan importir membayar selama 5 hari bukan 7 hari. 
Peraturan Kementrian Keuangan Republik Indonesia salinan peraturan Direktur Jenderal Bea dan Cukai Nomor : PER-16/BC/2016, menjelaskan dari tahap awal Pemberitahuan Barang Impor (PIB) sampai pada penerbitan Surat Persetujuan Pengeluaran Barang (SPPB) harus melalui Sistem Komputer Pabean (SKP), dan hasil penelitian menunjukkan bahwa Kantor Pengawasan dan Pelayanan Bea dan Cukai Tipe Madya Pabean C Manado juga melakukan prosedur penerbitan Surat Persetujuan Pengeluaran Barang (SPPB) dengan Sistem Komputer Pabean (SKP) atau secara online, yang secara langsung dengan mudah dapat di akses oleh importir.

\section{KESIMPULAN DAN SARAN}

\subsection{Kesimpulan}

Berdasarkan hasil penelitian dan pembahasan mengenai Prosedur Penerbitan Surat Persetujuan Pengeluaran Barang (SPPB) Pada Kantor Pengawasan dan Pelayanan Bea dan Cukai Tipe Madya Pabean C Manado, dapat disimpulkan bahwa :

Prosedur penerbitan Surat Persetujuan Pengeluaran Barang (SPPB) pada Kantor Pengawasan dan Pelayanan Bea dan Cukai Tipe Madya Pabean C Manado pada dasarnya sudah berjalan sesuai dengan peraturan Kementrian Keuangan Republik Indonesia salinan peraturan Direktur Jenderal Bea dan Cukai Nomor : PER-16/BC/2016 tentang Petunjuk Pelaksanaan Pengeluaran Barang Impor Untuk Dipakai.

Dalam peraturan Kementrian Keuangan Republik Indonesia salinan peraturan Direktur Jenderal Bea dan Cukai Nomor : PER-16/BC/2016 menjelaskan secara menyeluruh dari awal importir mengisi dan membuat Pemberitahuan Impor Barang (PIB) sampai pada penerbitan Surat Persetujuan Pengeluaran Barang (SPPB). Prosedur penerbitan Surat Persetujuan Pengeluaran Barang (SPPB) dalam hasil penelitian dapat dilihat dari perbandingan antara PER-16/BC/2016 dengan prosedur yang dilakukan oleh Kantor Pengawasan dan Pelayanan Bea dan Cukai Tipe Madya Pabean C Manado sudah mengikuti aturan.

\subsection{Saran}

Dari kesimpulan yang ada maka peneliti memberikan beberapa saran yaitu, Untuk Kantor Pengawasan dan Pelayanan Bea dan Cukai Tipe Madya Pabean C Manado agar terus meningkatkan kualitas dalam penerbitan Surat Persetujuan Pengeluaran Barang (SPPB), karena sekarang ini begitu banyak kegiatan impor yang terjadi didaerah pabean. Perlu ketelitian dalam hal pemeriksaan dari tahap importir mengisi dan membuat Pemberitahuan Impor Barang (PIB) sampai penerbitan Surat Persetujuan Pengeluaran Barang (SPPB) agar tidak terjadi impor barang yang dilarang masuk ke dalam daerah pabean serta tidak mengurangi pendapatan Negara.

Kantor Pengawasan dan Pelayanan Bea dan Cukai Tipe Madya Pabean C Manado juga harus berpatokan terhadap peraturan yang berlaku agar dapat menjalankan tugas dan tanggung jawab sesuai peraturan yang dibuat oleh pemerintahan Negara Republik Indonesia dalam rangka meningkatkan pendapatan Negara serta bisa menjalankan visi misi dari Kantor Pengawasan dan Pelayanan Bea dan Cukai Tipe Madya Pabean C Manado.

\section{DAFTAR PUSTAKA}

David Sandro Simorangkir. 2017. Evaluasi Implementasi Peranan Pengendalian Internal: Pelaksanaan Impor Sementara di Kantor Pengawasan dan Pelayanan Bea dan Cukai Tipe Madya X. Politeknik Keuangan Negara STAN.

Indrawati. 2015. Metode Penelitian Manajeman dan Bisnis. Aditama. Bandung.

Johanes Tene, Jullie J. Sondakh, Jessy D.L. Warongan. 2017. Pengaruh Pemahaman Wajib Pajak, Kesadaran Pajak, Sanksi Perpajakan Dan Pelayanan Fiskus Terhadap 
Kepatuhan Wajib Pajak (Studi Empiris Pada Wajib Pajak Irang Pribadi Yang Terdaftar Di KPP Pratama Manado). Universitas Sam Ratulangi Manado.

Juita Mohamad. 2012. The Impact of Tariff Reductions on Real Imports in Malaysia from 1980-2010. Waseda University Tokyo Japan

Kementrian Keuangan Republik Indonesia Salinan Peraturan Direktur Jenderal Bea Dan Cukai Nomor : PER-16/BC/2016. Tentang Petunjuk Pelaksanaan Pengeluaran Barang Impor Untuk Dipakai. .

Lina Ardi Arti. 2016. Proses Penanganan Custom Clearance Akibat Kesalahan Pemberitahuan Impor Barang Pada PT. Mitra Kargo Indonesia. Universitan Sebelas Maret.

Lubis Irsan. 2015. Mahir Akuntansi Pajak Terapan. Andi. Yongyakarta.

Mardiasmo. 2016. Perpajakan Edisi Terbaru 2016. Andi. Yongyakarta.

Pemerintah Republik Indonesia. 2006. Undang-Undang Republik Indonesia Nomor 17 Tahun 2006. Tentang Perubahan Atas Undang-Undang Nomor 10 Tahun 1995 Tentang Kepabeanan.

Purwito Ali \& Indriani. 2015. Ekspor, Impor, Sistem Harmonisasi, Nilai Pabean dan Pajak dalam Kepabeanan. Mitra Wacana Media. Jakarta.

Sugiyono. 2012. Metode Penelitian Kuantitatif Kualitatif dan R\&D. Alfabeta. Bandung.

Sumarsan Thomas. 2015. Perpajakan Indonesia. Indeks. Jakarta Barat.

Supriyanto, Edy. 2011. Akuntansi Perpajakan. Graha Ilmu. Yogyakarta. 